\title{
Toward Fabrication of Bioactive Papers: Covalent Immobilization of Peptides and Proteins
}

Valentina J. Liebich, Olga Avrutina, Jan Habermann, Laura M. Hillscher, Tobias Meckel, ${ }^{b}$ Markus Langhans, Markus Biesalski and Harald Kolmar

\section{Electronic Supplementary Information}

\section{H-GGGßAK(aminooxyacetic acid)AWGG-NH ${ }_{2}$}

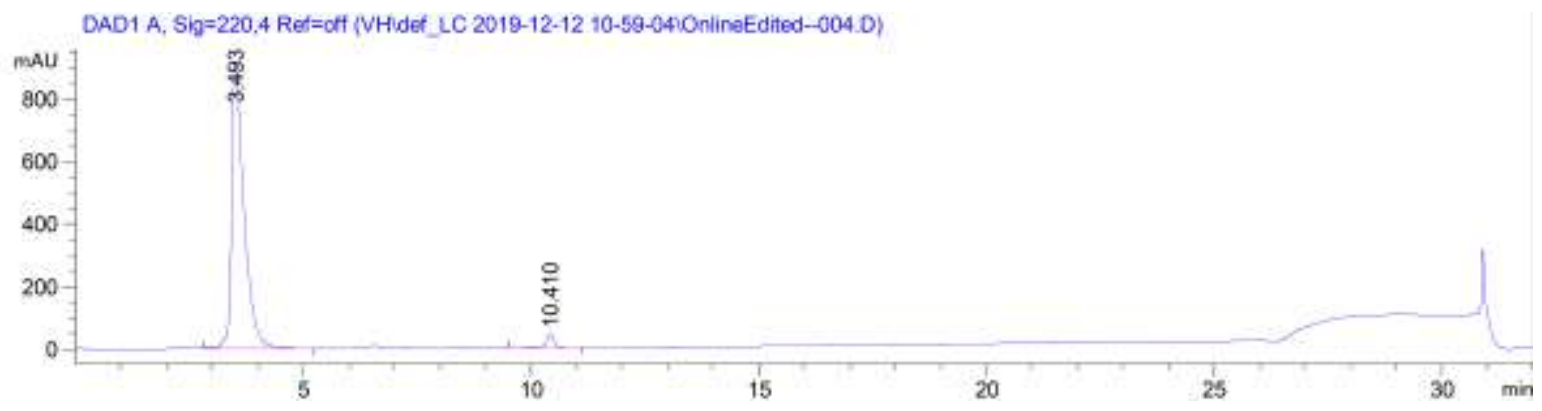

Figure S1. HPLC analysis of linker H-GGGßAK(aminooxyacetic acid)AWGG-NH ${ }_{2}\left(t_{R}=3.49 \mathrm{~min}\right.$ ) Performed with a gradient of $10-60 \%$ eluent B (90\% ACN) on an Agilent 1100 equipped with an Agilent Eclipse Plus RP column (C18, $100 \times 4.6$ mm, $3.5 \mu \mathrm{m}, 95 \AA$ Å).

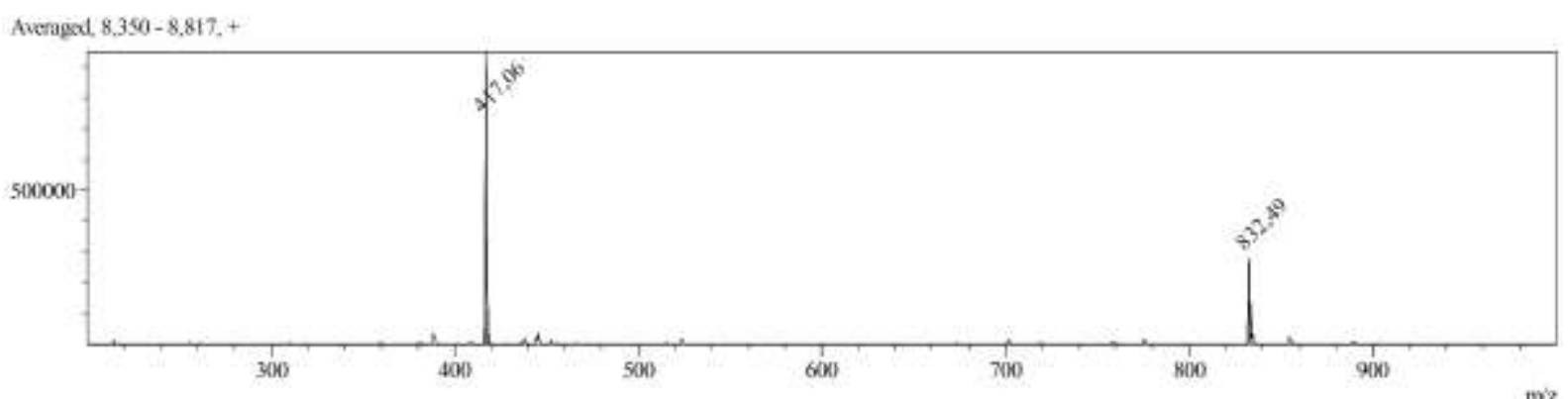

Segment\#1 $(\times 1.000 .000)$

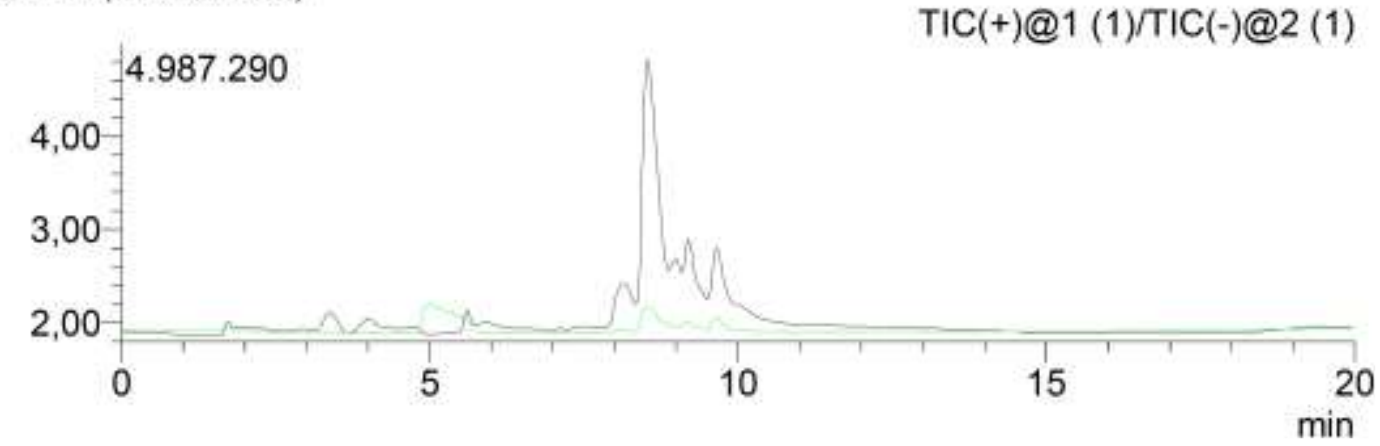

Figure S2. LCMS analysis of peptide linker H-GGG $\beta$ AK(aminooxyacetic acid)AWGG-NH $\mathrm{NH}_{2}$ 
Calculated MW: $832 \mathrm{~g} / \mathrm{mol}$; measured m/z: 417,06 $(\mathrm{M}+2 \mathrm{H})^{2+}, 832,49(\mathrm{M}+\mathrm{H})^{+}$.

2. mTG suitability for enzyme-promoted immobilization

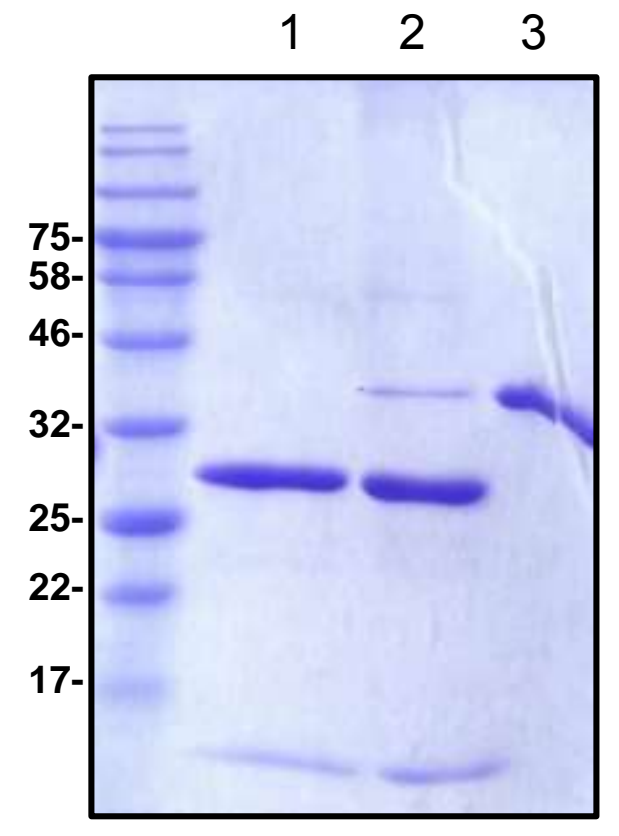

SDS PAGE analysis of tGFP crosslinking by microbial transglutaminase. Lane 1: tGFP-DIPIQGMTG only; lane 2: tGFP-DIPIGQGMTG incubated with mTG for $2 \mathrm{~h}$ at $37^{\circ} \mathrm{C}$ in solution; lane 3 : $\mathrm{mTG}$ only. no mTG-mediated tGFP crosslinking was observed.

\section{Primer sequences for cloning}

Table S1. Oligonucleotide sequences for cloning.

Oligonucleotide

pCT-tGFP-Ncol-up

pCT-tGFP-mTG-His6

Baml-lo
Sequence

5' - ATATATGGATCCATGGAAATTGAATGTCGTATTACC -3'

5'-ATATATGGATCCTTAGTGGTGGTGGTGGTGGTGGCCGGTCATGCCCTGGCC AATCGGAATATCTTCTTCACCGGCATC- ${ }^{\prime}$ 


\section{Paper fiber modification}

Table S2. Conductivity titration of cotton linters fibers (Grade 225 HSR-M, Buckeye Technologies)

\begin{tabular}{r|rrrrr}
\multicolumn{2}{c}{$\begin{array}{l}\text { Result 1 } \\
{[\mathrm{mol} / \mathrm{g}]}\end{array}$} & $\begin{array}{l}\text { Result 2 } \\
{[\mathrm{mol} / \mathrm{g}]}\end{array}$ & $\begin{array}{l}\text { Result 3 } \\
{[\mathrm{mol} / \mathrm{g}]}\end{array}$ & $\begin{array}{l}\text { Loading } \\
{[\mu \mathrm{mol} / \mathrm{g}]}\end{array}$ & $\begin{array}{r}\text { Standard } \\
\text { deviation } \\
{[\mu \mathrm{mol} / \mathrm{g}]}\end{array}$ \\
\hline $\mathbf{6}$ & $7.54 \mathrm{E}-06$ & $1.25 \mathrm{E}-05$ & $8.47 \mathrm{E}-06$ & 9.52 & 2.66 \\
$\mathbf{8}$ & $1.21 \mathrm{E}-05$ & $1.24 \mathrm{E}-05$ & $1.24 \mathrm{E}-05$ & 12.33 & 0.16 \\
$\mathbf{1 0}$ & $1.04 \mathrm{E}-05$ & $1.12 \mathrm{E}-05$ & $1.15 \mathrm{E}-05$ & 11.00 & 0.58 \\
$\mathbf{1 2}$ & $1.12 \mathrm{E}-05$ & $1.13 \mathrm{E}-05$ & $1.09 \mathrm{E}-05$ & 11.16 & 0.23
\end{tabular}

Table S3. Determination of aldehyde content

Blank fibers

$0.15 \mathrm{mmol} \mathrm{NaClO} / \mathrm{g}$

Aldehyde content $\mathrm{mmol} / \mathrm{g}$

0.0224

0.0649

Standard deviation

0.0013

0.0033 